\title{
(6) OPEN ACCESS \\ Exercise therapy in primary biliary cirrhosis: the importance of moving while sitting on a surgical waiting list—a case study
}

\author{
Kate Hallsworth, ${ }^{1}$ Laura Jopson, ${ }^{1,2}$ David E Jones, ${ }^{1,2}$ Michael I Trenell ${ }^{1}$
}

\begin{abstract}
${ }^{1}$ Institute of Cellular Medicine, Newcastle University, Newcastle upon Tyne, UK

'Liver Unit, The Newcastle Upon Tyne Hospitals NHS Foundation Trust, Newcastle upon Tyne, UK
\end{abstract}

\section{Correspondence to}

Dr Kate Hallsworth, MoveLab, 4th Floor William Leech Building, Newcastle University, Newcastle upon Tyne NE2 4HH, UK; kate.hallsworth@ncl.ac.uk

Received 7 December 2015 Accepted 18 December 2015 Published Online First

12 April 2016

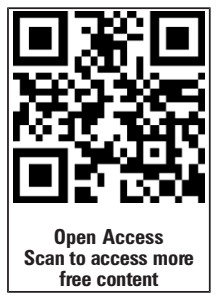

\section{CrossMark}

To cite: Hallsworth $\mathrm{K}$, Jopson L, Jones $\mathrm{DE}$, et al. Frontline Gastroenterology 2016:7:167-169.

\begin{abstract}
Background It is being increasingly recognised that reduced cardiorespiratory fitness is associated with poorer outcomes after major surgery. Exercise limitation and reduced aerobic capacity are common in people with end-stage liver disease. There is limited evidence about the role of exercise therapy in the management of primary biliary cirrhosis (PBC) and no studies have looked at the effect of exercise in people with PBC who are awaiting liver transplantation. This case study is the first to report that personalised exercise therapy improves cardiorespiratory fitness in a patient with PBC without worsening symptoms of severe fatigue. Methods Cardiopulmonary exercise testing was used to assess cardiorespiratory fitness in a patient with end-stage PBC prior to listing for transplantation. A personalised exercise programme was designed to improve cardiorespiratory fitness while the patient was on the transplant waiting list.

Results Anaerobic threshold, $\mathrm{VO}_{2 \text { PEAK }}$ and maximum workload all improved with regular exercise. Fatigue levels remained unaltered.

Conclusions This patient tolerated and adhered to a personalised exercise programme for a prolonged period of time while awaiting surgery despite significant fatigue and disease burden. Liver transplantation was successfully completed and this woman remains well over 2 years postsurgery.
\end{abstract}

\section{INTRODUCTION}

Primary biliary cirrhosis (PBC) is a chronic cholestatic liver disease with an autoimmune aetiology. A minority of patients with $\mathrm{PBC}$ can progress to endstage liver disease and the need for liver transplantation. Fatigue is commonly associated with $\mathrm{PBC}$ and approximately $20 \%$ of patients will experience severe fatigue which can limit physical activity and often has a negative impact on quality of life. This decrease in daily physical activity results in general deconditioning and reduced cardiorespiratory fitness. Physical deconditioning can pose a problem if the patient is to be considered for liver transplantation, as cardiorespiratory fitness forms part of the assessment of anaesthetic and overall surgical risk. Patients that have better cardiorespiratory fitness prior to undergoing major hepatobiliary surgery have been shown to have improved peri-operative and post-operative outcomes, with lower complication rates. ${ }^{1}$ Indeed, people with low cardiorespiratory fitness are at increased risk of mortality within 100 days post liver transplantation. ${ }^{2}$ We trialled a period of pre-operative exercise therapy in a patient with $\mathrm{PBC}$, prior to listing for liver transplantation, with the aim of improving cardiorespiratory fitness, a key biomarker of surgical morbidity and mortality. We also assessed the impact of regular exercise on patient fatigue.

\section{PRESENTATION OF THE CASE}

A 44-year-old woman with $\mathrm{PBC}$ was referred for consideration of liver transplantation due to intractable pruritus. She had been diagnosed with PBC in 2007, treated with ursodeoxycholic acid (UDCA) but suffered with severe fatigue and intractable pruritus which had been resistant to all anti-pruritic therapies including molecular adsorbent recirculating system. At the time of liver 
Table 1 Exercise test results, fatigue and physical activity data

\begin{tabular}{|c|c|c|c|c|c|c|c|c|}
\hline & \multicolumn{3}{|l|}{ CPET results } & \multirow{2}{*}{$\begin{array}{l}\text { Fatigue } \\
\text { FIS }\end{array}$} & \multicolumn{4}{|c|}{ Physical activity data (daily means) } \\
\hline & $\begin{array}{l}\mathrm{AT}(\mathrm{mL} / \mathrm{kg} / \\
\mathrm{min})\end{array}$ & $\begin{array}{l}\mathrm{VO}_{2 \text { PEAK }} \\
(\mathrm{mL} / \mathrm{kg} / \mathrm{min})\end{array}$ & $\begin{array}{l}\text { Max work } \\
\text { rate (watts) }\end{array}$ & & Steps & $\begin{array}{l}\text { Energy } \\
\text { expenditure } \\
\text { (kcal) }\end{array}$ & $\begin{array}{l}\text { Average } \\
\text { METS }\end{array}$ & $\begin{array}{l}\text { Physical activity } \\
\text { duration (min) }\end{array}$ \\
\hline April 2010* & 8.8 & 13.4 & 66 & - & - & - & - & - \\
\hline July $2010 \dagger$ & 9 & 19 & 86 & 120 & 5822 & 1722 & 1.3 & 44 \\
\hline September 2010 & 16 & 20 & 102 & 115 & 7701 & 1884 & 1.4 & 92 \\
\hline December 2010 & 10 & 21 & 80 & - & 6931 & 1757 & 1.3 & 48 \\
\hline January 2011 & 14 & 22 & 109 & - & - & - & - & - \\
\hline May 2011 & 10 & 20 & 105 & 107 & 5869 & 1727 & 1.3 & 43 \\
\hline July 2011 & 12 & 22 & 115 & 125 & 6638 & 1754 & 1.3 & 53 \\
\hline
\end{tabular}

* Results from initial CPET.

tResults from second CPET prior to undertaking exercise programme.

AT, anaerobic threshold; CPET, cardiopulmonary exercise test; FIS, Fatigue Impact Scale; METS, metabolic equivalents.

transplant assessment she was a non-responder to UDCA but bilirubin and liver synthetic function were normal, model for end-stage liver disease (MELD) was 6 and UK end-stage liver disease (UKELD) 45. The transplant assessment did not identify any contraindications to transplantation, however concern about cardiorespiratory fitness was raised as cardiopulmonary exercise test (CPET) revealed a low anaerobic threshold (AT) of $8.8 \mathrm{~mL} / \mathrm{kg} / \mathrm{min}, \mathrm{VO}_{2 \text { PEAK }} 13.4 \mathrm{~mL} / \mathrm{kg} / \mathrm{min}$ and maximum cycle power output of 66 watts. The multidisciplinary team decided to refer the patient to the MoveLab at Newcastle University for further exercise testing (see Hallsworth $e t a l^{3}$ for CPET protocol) with a view to implementing a personalised home exercise programme to improve her general fitness prior to listing for transplantation.

An exercise programme was designed to focus on strengthening leg and respiratory muscles, and improving general cardiorespiratory fitness. All exercises were completed on a static bicycle in the patient's home. The exercise intensity was guided by the 'rating of perceived exertion scale ${ }^{4}$ and was based on the concept of interval training which interspersed 'hard' bursts of exercise with active recovery. Intervals initially lasted for $30 \mathrm{~s}$ with a maximum of 2 min active recovery in between. The patient tried to complete 10 hard intervals per session but this had to be adjusted according to the patient's fatigue levels on each particular day. The patient aimed to complete the programme 3-4 times/ week and was contacted at regular intervals to check adherence and to modify the programme as necessary.

Physical activity levels were assessed objectively using a multisensor array (SenseWear Pro Bodymedia, Pennsylvania, USA) for 7 days prior to starting the exercise programme, and for 7 days after subsequent visits. Fatigue was assessed using the Fatigue Impact Scale. ${ }^{5}$ See table 1 for results.

\section{RESULTS}

AT, $\mathrm{VO}_{2 \text { PEAK }}$ and maximum work all improved markedly from initial CPET testing (see table 1). Results fluctuated over the time course of the exercise programme depending on how the symptoms of PBC were affecting daily life and we would expect improvements to taper off as the person moves into the maintenance phase of an exercise programme. Fatigue levels did not alter. Physical activity levels remained relatively unchanged despite an increase in cardiorespiratory fitness.

Orthotopic liver transplantation was successfully carried out in August 2013 and 2 years on this woman remains well post surgery.

\section{DISCUSSION}

This case study demonstrates for the first time that exercise therapy can improve cardiorespiratory fitness in patients with end-stage $\mathrm{PBC}$ without worsening the symptoms of fatigue. This patient tolerated and adhered to a personalised exercise programme for a prolonged period of time while awaiting surgery despite significant fatigue and disease burden with physiological benefits (as demonstrated by an improvement in AT). Without 'pre-habilitation' to improve aerobic fitness, this woman may not have been a viable candidate for major surgery and may not have had such a positive surgical outcome. Patients should not be excluded from consideration for liver transplantation on the basis of low cardiorespiratory fitness as this can be improved with guided home exercise. Despite an increase in cardiorespiratory fitness, day-to-day physical activity levels remained unchanged and this may be due to the high levels of chronic fatigue experienced by the patient.

Future work is needed to investigate the peri-surgical and post-surgical effect of cardiorespiratory fitness levels on recovery post liver transplantation. A large-scale study is also warranted to evaluate the effectiveness and feasibility of pre-operative exercise therapy prior to liver transplantation.

Twitter Follow Michael Trenell at@miketrenell 
Contributors All authors contributed to the clinical care of the patient and to the preparation of this manuscript.

Funding The National Institute for Health Research (NIHR)

Newcastle Biomedical Research Centre for Ageing and Age

Related Disease based at Newcastle upon Tyne Hospitals NHS

Foundation Trust and Newcastle University, Medical Research Council (Grant number G0700718 for KH), NIHR/Higher Education England (Grant number NIHR-SRF-2011-04-017 for MIT).

Competing interests None declared.

Patient consent Obtained.

Provenance and peer review Not commissioned; internally peer reviewed.

Open Access This is an Open Access article distributed in accordance with the terms of the Creative Commons Attribution (CC BY 4.0) license, which permits others to distribute, remix, adapt and build upon this work, for commercial use, provided the original work is properly cited. See: http://creativecommons.org/licenses/by/4.0/

\section{REFERENCES}

1 Snowden CP, Prentis J, Jacques B, et al. Cardiorespiratory fitness predicts mortality and hospital length of stay after major elective surgery in older people. Ann Surg 2013;257:999-1004.

2 Epstein SK, Freeman RB, Khayat A, et al. Aerobic capacity is associated with 100-day outcome after hepatic transplantation. Liver Transpl 2004;10:418-24.

3 Hallsworth K, Fattakhova G, Hollingsworth KG, et al. Resistance exercise reduces liver fat and its mediators in non-alcoholic fatty liver disease independent of weight loss. Gut 2011;60:1278-83.

4 Borg GA. Psychophysical bases of perceived exertion. Med Sci Sports Exerc 1982;14:377-81.

5 Fisk JD, Ritvo PG, Ross L, et al. Measuring the functional impact of fatigue: initial validation of the fatigue impact scale. Clin Infect Dis 1994;18(Suppl 1):S79-83. 